the O-ring joint should have been redesigned years before. The O-rings were known not to perform according to the original design because the thin casing flexed unexpectedly and the joints tended to widen when the rockets exploded into life. But the O-rings had always worked, and the pragmatic approach became "normalized'. In retrospect it was not so difficult for Feynman to show that the shuttle the American public had been led to believe. But in retrospect it was a far more dangerous machine than anybody believed, or they would not have launched it. It was nobody's intention to kill the astronauts or lose their own jobs.

Feynman concluded that, given the state of the shuttle at the time of Challenger, the chances of disaster from one cause or another were between one and two in a hundred - that is, the shuttle programme could expect between 1 and 2 per cent fatalities. Subsequently, NASA has spent a great deal of money to reduce the risk, but I wonder if it is worth it.

I have been lucky enough to watch a shuttle launch (the night-launched Hubble Space Telescope repair mission). I found myself deeply moved by fearful empathy for the fragile humans sitting on that column of fire gradually dwindling to was a far more dangerous machine than

a distant star, but I would volunteer for the ride in a trice even after reading these two books. Thirty workers were killed building the Golden Gate Bridge, and they were not volunteers. If only we could find a way of spending the shuttle improvement money on those who take risks because that is the only way they can earn a living, accept that it is in the nature of pioneering technology to be risky and get on with it. Of course, when it is not volunteers' lives that are at risk but communities of innocent people, as in nuclear power engineering, the moral is completely turned around; in such circumstances those who argue that complex technology can be made safe are deeply culpable.

The danger of the simple folk tale of Challenger, which safeguards the science at the expense of the managers, is that it strengthens the idea that complex technology is perfectible. Vaughan's book shows why we should not believe it; we make our technology and we can control and understand it, but only to the extent that we can control and understand ourselves.

Harry Collins is at the Centre for the Study of Knowledge, Expertise and Science, University of Southampton, Southampton S017 1BJ, UK.

\section{Self-fulfilling prophecies}

\author{
David Edgerton
}

Knowing Machines: Essays on Technical Change. By Donald MacKenzie. MIT Press: 1996. Pp. 338. \$35, £22.50.

ENGINEERS have long argued that one of the principal problems of modern society has been its slow adaptation to the needs of the new technologies they created. In the nineteenth and twentieth centuries, some engineers such as Herbert Spencer went on to be pioneers of the new science of sociology. After 1945, engineers urged the development of industrial sociology and the taking into account of the 'human factor' in industry. They generally took the view that modern technologies appeared almost out of nowhere, and at an advancing rate, but societies and cultures had no tendency to change, except belatedly under the influence of new technologies. The resulting 'cultural lag' meant not only that technologies were too slowly applied but, more importantly, that they were inappropriately applied: to war, to the creation of unemployment and so on. The scientific study of society promised to produce a kind of social engineering that would reduce the lag and ensure that technology was properly used.

The same sort of arguments are still to be found in popular discussions of tech- nology and society; we are constantly told we are not ready for this or that technoldeficient. But academic sociology's approach to technology has moved on. In the late 1960s and 1970s, notably in Edinburgh, a group of sociologists, historians and philosophers argued that sociology, born out of science, should be applied to the study of science itself. This was a daring and controversial move, not least because it suggested that social factors went into the making of scientific knowledge. The 'Edinburgh School' developed - from the standard canons of scientific method - a series of prescriptions as to how one should study science. Perhaps the most famous was the symmetry principle: that the same analytical tools should be applied to studying all science, whether 'good' or 'bad'.

In the case of technology, this prescription amounts to saying that we should not explain the success of a technology by assuming its intrinsic superiority, while accounting for the failure of good technology by invoking social factors. Both technical and social factors should be involved in discussions of success and failure. Donald MacKenzie has been one of the pioneers of applying these powerful tools to technological knowledge (both formal ogy and that public understanding is and tacit) and to technological innovation in particular. The approach yields a rich account of invention and innovation far from the banal stories of heroic invention by unique people 'ahead of their time'.

MacKenzie's introductory essay provides the clearest guide I know to the methods and concerns of the new sociology of technological knowledge and innovation. It is especially attractive because it deals seriously with a least some of the criticisms of his approach, and distances itself from some of the excesses. MacKenzie focuses on such issues as who new technology is best for, the path-dependence of innovation, the need for symmetrical explanation of success and failure, the importance of self-fulfilling and selfnegating prophecies in technological innovation and the importance of the study of formal and tacit knowledge in technology.

Reprinted from a wide variety of sources, including Nature, Technology and Culture and the American Journal of Sociology, the essays in the book cover an amazing mix of topics in great depth and with great subtlety. MacKenzie is a fluent writer who avoids jargon and presents theoretical arguments lucidly. His historical narratives are tightly constructed and rich in detail.

Many of the studies are concerned with the history of computation, especially in relation to the military. The author outlines the influence of two laboratories, Los Alamos and Livermore, on the design and specification of supercomputers. They defined, he argues, what a supercomputer should be. He also provides an acute biographical sketch of Seymour Cray (written with Boelie Elzen), the most famous supercomputing entrepreneur.

Sociologists of knowledge have been traditionally very alert to controversies in science and technology, because they provide a glimpse into the nature of science and technology that is closed off when sciences and technologies settle down to a consensus. Of particular interest are MacKenzie's accounts of debates about computer-generated proofs of the integrity of computer programs.

MacKenzie is also concerned with competition between technologies, and provides a fine account of the development of the laser gyroscope for inertial navigators in civil aircraft. His point is that the early laser gyros were not manifestly superior or even superior at all to mechanical gyros. But it was believed that they would be and as a result they partially became so, because of the shift of development resources from mechanical to optical systems. So we should not assume from the ultimate success of the laser gyroscope that its victory was a foregone conclusion. Things could have turned out differently.

One of the great propaganda clichés of the nuclear age is that 'we can't uninvent nuclear weapons'. MacKenzie (writing in 
this case with Graham Spinardi) shows that this argument rests on a very particular account of the nature of science and technology. They argue that the science and technology of nuclear weapons relies on the constant performance of particular sorts of experiments, and a great deal of highly specific tacit knowledge. Nuclear technology has been built up in only a very few states, and with extraordinary difficulty. The capacity to build weapons could in practice disappear, even if all the science stayed in the public domain. The ultimate science-based weapon relies on much more than written knowledge and standard engineering capabilities.

In some ways MacKenzie is attacking straw men in his discussion of technological innovation, but this is not really a criticism of MacKenzie. It is, rather, a criticism of the way that we think and write about technology. We look at technologies in much the same way as they appear in advertisements: as fully formed, perfect and inevitable developments following a logic of technical development. The real world of new machines is very different, as we know from our own experience as well as from historical studies and MacKenzie's detailed empirical work.

David Edgerton is at the Centre for the History of Science, Technology and Medicine, Imperial College, London SW7 2AZ, UK.

\section{Taking things at interface value}

\section{Graham Farmelo}

Software for the Self: Culture and Technology. By Anthony Smith. Faber: 1996. Pp. 128. £7.99, (pbk).

Cultural Babbage: Technology, Time and Invention. Edited by Francis Spufford and Jenny Uglow. Faber: 1996. Pp. 290. £15.99, \$24.95 (pbk).

ACCORDING to Oscar Wilde, "all art is quite useless", and, to the extent that such a brutally utilitarian view is valid, the same is true of culture. Because part of the value of culture lies in its transcendence of the material world, it appears to be very different from technology, which is concerned only with the materially useful. What, then, is the place of technology in culture?

Information technology - the defining technology of our age - poses particularly difficult problems for the cultural theorist. Something so widely available to so many is not readily accommodated in a view of a culture based on what that austere critic Matthew Arnold identified as "the best that has been known and said in the world". It is unlikely that he would have found much "sweetness and light" in the hegemony of the silicon chip.

In Software for the Self, Anthony Smith examines the slippery concept of culture and examines its meaning in the light of modern technological developments in the media. The book is a collection of thoughtful and eclectic essays based on lectures the author gave in 1994, in a series named after T. S. Eliot, Arnold's twentiethcentury standard-bearer. Smith begins by explaining how the 'arts' - that broadest of portmanteau terms - came to be central to the usual narrow idea of what constitutes cultural activity. This leads him to analyse how the century's most pervasive cultural revolution has been effected electromagnetically, through the introduction of broadcasting media.

Smith makes a powerful case for the

importance of the concept of information in analysing the modern cultural agenda. He points out that information is a classic example of a transforming concept that, like chaos, the unconscious mind and the uncertainty principle, "rapidly invades every science, and its analogues and derivative images spread through the arts and into political discourse, eventually arriving at the gates of government". Scarcely a branch of modern industrial society has not been transformed by its own contact with the new paradigm of information, and we are all trying to come to terms with the potential of a global communica-

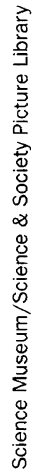

\section{IMAGE UNAVAILABLE FOR COPYRIGHT REASONS}

Prototype computer: Babbage's first "Difference Engine".

tions network, which promises to make most media readily available to anyone with a computer.

Smith points out that, with virtual reality still in its infancy and the potential for interactivity with the conventional media still largely unexplored, there are more cultural upheavals in the offing. Yet he pays little attention to the effects that the growth in the quantity of information in the media have had on the quality of the material purveyed. Has anything of significant literary worth ever been created in cyberspace? Perhaps it is a coincidence that it is in the adolescence of the digital age that such a question is regarded as misconceived or, at least, outré.

Smith has given us a valuable new perspective on contemporary culture in these fine essays, all happily devoid of jargon and snobbery. It is regrettable that he been so badly let down by his publishers. They tell us next to nothing about him, fail to provide him with an index (essential in a work of this breadth) and make no effort to package his book so that it might stand a chance of attracting the wide audience it deserves.

The unity of purpose that gives such collective power to Software for the Self is not evident in Cultural Babbage, a collection of pieces that idiosyncratically explore connections between science and technology (rarely distinguished here, regrettably) and various branches of the arts and humanities. Its 14 contributors include critics, poets, biographers and historians, each of them plainly at home in both of C. P. Snow's 'two cultures', in so far as they exist separately.

The theme of most of these essays is the place in the firmament of culture occupied by technology, in particular by machines and other inventions. As the title of the collection hints, a central figure here is Charles Babbage, the irascible polymath best remembered for his failure to build a complete version of what would probably have been regarded as the first computer. Doron Swade's elegant and scrupulously fair analysis of Babbage's reputation is followed by the highlight of the volume, Simon Schaffer's "Babbage's dancer and the impresarios of mechanism". This densely argued piece looks at how the tough-minded Babbage and his peers were fascinated by apparently frivolous automata, such as the silver danseuse that he exhibited, close to the unfinished portion of his first 'Difference Engine', in his London salon. Schaffer links this fascination with the perception of machine intelligence, which he convincingly argues "hinges on the cultural invisibility of the human skills which accompany them".

The quality of the other pieces is uneven but they do include some gems, notably Lavinia Greenlaw's look at the connections between science and poetry, Neil Belton's analysis of the British scorn of the scientific, and Jon Katz's advocacy of the republican revolutionary Thomas Paine as the spiritual father of the Internet. The excellent index makes the collection a valuable work of reference, although the bibliographical information is disappointing, to say the least.

In her introduction, Jenny Uglow remarks that the essays are "ballasted by 